\title{
Sustainability Learning in Organizations: The Role of Human Resource Development and Proposed Framework
}

\author{
Murni Zarina Mohamed Razalia*,, Rossilah Jamil ${ }^{b}$ \\ aUniversiti Teknologi Mara (UiTM), Kampus Puncak Alam, Bandar Puncak Alam, 43200, Selangor, Malaysia \\ ${ }^{b}$ UTM International Business School, Universiti Teknologi Malaysia, 54100, Kuala Lumpur, Malaysia \\ *Corresponding author: murni2309@gmail.com
}

\begin{abstract}
Learning through training and development programmes has been seen as an important vehicle to embed sustainability in organizations. This paper aims to conceptualize a model of sustainability learning in organizations and to understand the pivotal role that Human Resource Development plays in facilitating the learning process. It also explores relevant contextual factors that may influence the learning process engaged by employees in developing knowledge about sustainability. To fully understand the process of sustainability learning in organizations, this paper analyzes relevant theories on sustainability, Human Resource Development and learning theories. Results of the literature review will act as a basis to propose a framework which future researchers may refer to in studying sustainability learning in organizations. The proposed framework shall act as a point of departure to the development of holistic sustainability learning model through initiatives of Human Resource Development.
\end{abstract}

Keywords: Sustainability learning; human resource development; contextual factors

(C) 2016 Penerbit UTM Press. All rights reserved

\subsection{INTRODUCTION}

The concept of sustainability has attracted much attention from both profit and non-profit institutions. Many organizations have actively committed themselves with sustainability activities and linked them to their goals and strategies. The terms sustainability and sustainable development are typically used interchangeably given their synonymous meanings (Waas et al, 2011). From a business standpoint, sustainability refers to organizational practices that not only emphasize profits, but reflects the company's commitment towards achieving environmental and social impacts. Sustainability in the organization strategy has spread into almost every business functions including human resource. Human Resource (HR) has to play an important role in realizing the mission and vision of the company towards sustainability through the strategic HR.

One of the most important activities of HR in realizing sustainability goal is Human Resource Development (HRD) due to its ability in leveraging employees' performance (Garg, 2014). There have been several studies highlighted the pivotal role of HRD in achieving the sustainability goal of organizations (Garavan and McGuire, 2010; Kim, 2012; Russ, 2012; Ardichvili, 2013). The HRD roles include promoting and engaging members of organizations with sustainability activities such as culture change effort, training programmes and learning activities that focus on increasing sustainability awareness within the organizations. Training and development has been considered a major platform of learning in organizations because it helps employees to acquire the required knowledge, skills, competencies, attitudes or behaviours to achieve organizations' goals (Armstrong, 2001 and Noe, 2013). Therefore, to realize sustainability goal of the organization, the value of learning should be recognized by initiating training and employee development in the organization.

\section{Problem Statement}

Sustainability is not a destination that one can reach but rather is a continuous learning process (Wals \& Rodela, 2014). Successful learning has been considered vital to achieve organizational sustainability (Henry, 2009; Velazquez et.al., 2011; Erskine and Johnson, 2012; Schneider et.al., 2013; Dlouha, et.al., 2013; Lankester, 2013;Craig and Allen, 2013; Moyer et.al, 2014). It was generally agreed that an increased understanding of the sustainability learning processes will help the organizations to cultivate sustainability learning (Fabricatore and Lopez, 2012; Lankester, 2013; Craig and Allen, 2013; Schneider et.al, 2013; Dlouha, et.al, 2013 Moyer et.al., 2014). There have been several attempts to map and understand sustainability learning in organizations. To illustrate, the sustainability learning framework by Henry (2009) focuses on mapping two learning mechanisms, i.e. individual learning and social learning, with the type of learned knowledge by corresponding four types of learning challenges. Elsewhere, Lankester (2013) developed a framework to analyse the what, why and how an individual learns sustainability based on adult learning theories that embody transformative and experiential learning. On the same note, Moyer et.al (2014) explores individual learning for sustainability based on Mezirow's transformative learning theory with two other learning 
domains namely instrumental and communicative learning. Other studies by Dlouha, et.al (2013) and Wals and Rodela (2014) focused their attention on social learning to develop a framework for sustainability learning. Fabricatore and Lopez (2012) have explored the potential of digital games in the process of sustainability learning which based on system thinking and problem solving approach. On the other hand, Zakirah and Amran (2011), have studied the utilization of electronic learning through persuasive learning which they have found effective in promoting sustainability.

These previous attempts however fall short in some areas. Firstly, they fail to take into account relevant contextual factors which may be important to accurately understand how sustainability learning takes place and problems it may face in different environments (Henry, 2009; Wals and Rodela, 2014; Moyer, et.al 2014). Secondly, the process that an individual engages in the sustainability learning is somehow still a mystery (Lankester, 2013; Moyer et.al, 2014). Thirdly, as Lankester (2013) has pointed out, the available models have not adequately looked into the pre, during and post learning processes. Given these limitations, some scholars (for example Henry, 2009; Lankester, 2013; Moyer et al, 2014; Wals and Rodela, 2014) have suggested that future research efforts to formulate sustainability learning model should consider and empirically test not only all the relevant contextual and socio-demographical factors of organizations and their learners, but also the whole dynamism of the learning process. In addition to this, social learning theory that corresponds with relevant contextual factors can also be extensively explored since it will provide a space for holistic view for sustainability learning (Dlouha, et.al 2013; Wals and Rodela, 2014). Besides that, the source of information (for example, social media) has to be considered in future studies since it also has been accepted as a tool to facilitate employees' sustainability learning process (Hansmann, 2010; Craig and Allen, 2013).

HRD has a promising role in facilitating sustainability learning in organizations. Connection between HRD scholars and practitioners in sustainability will provide a room for the creation of new and powerful conceptual and framework in addressing gap in this field (Kim, 2012; Russ, 2012). Training and development programmes have been recognized in contributing to sustainability awareness (Thomas and Lamm, 2012; Ardichvili, 2013), sustainable business practices (Garavan and McGuire, 2012; Kim, 2012 ; Russ, 2012 ;) and sustainabilityoriented technical skills (Thomas and Lamm, 2012). Thus, exploring the role of HRD in facilitating the sustainability learning process presents a research-worthy area for further understanding the topic.

Combining the knowledge regarding the current limitations of sustainability learning models and the vast potential roles of HRD in promoting organizational sustainability, this paper adopts literature analysis with the aim to produce a framework which can serve as a general guideline for future researchers in the area. The framework shall provide a holistic overview of the myriad of factors which may be involved in sustainability learning in organizations through HRD programmes.

\subsection{LITERATURE REVIEW}

\section{Defining Sustainability}

The terms sustainability and sustainable development, despite of some debates on the extent of their similarities (eg. see Diesendorf, 2000), are often used interchangeably and have been treated as synonyms (Brown, et.al 1987; Waas et al, 2011). A review of the literature reveals that the concept of sustainability has received various interpretations depending on its context (Brown, et.al 1987; Morelli, 2011; Batra, 2012) and its authors (Saadatian et al, 2012). In business context, sustainability is associated with the ability of business organizations to be committed in achieving economic, social and environmental impacts, which also known as Triple Bottom Line (DeLong and Mehalik, 2013). On the same note, Wagner and Svensson (2014) refers sustainability by incorporating the issues of economic, social and environmental into consideration for the sake of business relationship with the society. It is argued that business performance needs to be measured against sustainability-based benchmarks focusing on the 3P (people, profit and planet) that have changed the emphasis from profitability to social responsibility and shareholder to stakeholder orientation (Batra, 2012). In the context of retail business, sustainability means cutting cost by reducing raw material waste or minimizing carbon production (Emery, 2013). Business sustainability can be achieved through proper strategies of the organization (Muthuveloo and Ping, 2013). For Bansal and DesJardine (2014), business sustainability is defined as the ability of organizations to respond to their short-term financial needs without compromising their ability to meet other or future needs. 
Table 1 Sustainability definitions in different contexts

\begin{tabular}{|l|l|l|}
\hline Authors & Definitions & Contexts \\
\hline Brundtland Commission (1987) & $\begin{array}{l}\text { The present development in fulfilling needs and wants without jeopardizing the } \\
\text { future generations' needs and wants. }\end{array}$ & $\begin{array}{l}\text { The definition has been widely used in } \\
\text { various contexts (Wiersum, 1995). }\end{array}$ \\
\hline Brown, et al (1987) & $\begin{array}{l}\text { Sustainability may have different interpretation depending on the context of } \\
\text { concern such as social concerns, ecological and economic sustainability. }\end{array}$ & Multiple perspectives \\
\hline Wiersum (1995) & Don't harvesting more than what the forest yields in the new growth & Forestry \\
\hline Moreli (2011) & $\begin{array}{l}\text { "Meeting the resource and services needs of current and future generations } \\
\text { without compromising the health of the ecosystems that provide them" (2011: } \\
\text { 24). }\end{array}$ & Environmental \\
\hline Shaharir and Alinor (2013) & $\begin{array}{l}\text { "Sustainability is the state whereby present physical, social, political, economic, } \\
\text { knowledge, spiritual-religious and the survival of language and culture are } \\
\text { achieved and at the level of wistdo without sacrificing related resources and all } \\
\text { creatures created by God so that future generations can enjoy happiness in this } \\
\text { life and in the next world, at the very least as good as this generation" (2013: } \\
\text { 270). }\end{array}$ & $\begin{array}{l}\text { (i.e. } \\
\text { civilization and Islamic perspective) }\end{array}$ \\
\hline Bansal and Desjardine (2014) & $\begin{array}{l}\text { "Ability of the firms to respond to their short-term financial needs without } \\
\text { compromising their (or others') ability to meet their future needs" (2014: 71). }\end{array}$ & Business perspective \\
\hline
\end{tabular}

The above table points out that the concept of sustainability is not new. Majority of the previous studies have been inspired by the definition of sustainability introduced by Brundtland Commission. Environmental management can be seen as the main discipline contributing to the development of sustainability area. This paper adopts the definition proposed by Diesendorf (2000), i.e. "sustainable development comprises types of economic and social development which protect and enhance the natural environment and social equity" (p. 19-37).

Sustainability Theory - Triple Bottom Line

There are several theories to explain the concept of sustainability. They include the Triple Bottom Line (Elkington, 1997), the egg of sustainability (Guijt and Moiseev, 2001), prism of sustainability (Stenberg, 2001), Atkisson's Pyramid model (Atkisson,et.al, 2004), four capital model (Ekins and Medhurst, 2003) and some others. However, the Triple Bottom Line theory will be the focus of this article.

The Triple Bottom Line (TBL) is one of the most common concepts in sustainability. Coined by John Elkington in 1990s, TBL is encompassed into the accounting framework used to measure the performance of American corporations in terms of three areas, i.e. people, planet and profits (Elkington 1994). TBL also has proposed advance sustainability agenda by encouraging the economic value success, the social equity and ecosystem quality. TBL has speed up the development of lifecycle and value impact assessment, and at the same time has expanded the concept of corporate social responsibility in business organizations (McBride, 2011). At the upper level, TBL is a valuable aspiration that explicitly acknowledges the importance of organization's economic performance and social environments (Colbert and Kurucz, 2007). The users of TBL are businesses, non-profit and government entities. For business, TBL are compelling due to its evidence in for the greater long-term profitability. For example, economically, it may affect the amount of taxes paid, socially, the employees training increased which bring welfare to career retention plus the charitable contribution and environmentally greenhouse gas emission, amount of waste and incident rate has decreased (Slaper, 2011).

\section{Sustainability Learning}

The terms 'learning for sustainability' and 'sustainability learning' are used to explain the learning process to embed sustainability (Henry, 2009; Fabricatore and Lopez, 2012; Lankester, 2013; Duggan, et. al., 2014). However, Hansmann (2010) has provided a specific definition of sustainability learning that refers to "the learning of individuals and human systems such as groups, organizations and human societies, which aim to achieve and facilitate sustainable development". It is highly acknowledged that learning is crucial in fostering sustainability (Velazquez, et.al 2011; Lankester, 2013; Coleman, 2013; Dlouha, et. al., 2013; Wals and Rodela, 2014; Moyer, et. al., 2014). The learning process involves a critical reflection through participation and experimentation of learners (Lankester, 2013).

Learning refers to "the process by which the actors assimilate information and update their cognitions and behaviour accordingly" (Henry, 2009: 131). Noe (2013) defines learning as "a relatively permanent change in human capabilities that including knowledge, skills, attitudes, behaviour and competencies that are not the result of growth process" (2013; p.152). Knowles, et. al. (2011) agree that learning involves change by the acquisition of habits, knowledge and attitudes. The changes will enable the individual to make personal and social judgements. In regards to sustainability, Velazquez,et.al (2011) urged that, sustainability learning process is considered as a kind of trial and error method that need to be reviewed and analysed constantly. In addition to this, the learning sustainability experience will provide the companies with the powerful tool in balancing the economic profits with environment and communities in the organization.

There have been several attempts to explore sustainability learning by studying the process based on several learning theories. In a study conducted by Lankester (2013), a framework based on adult learning theories was developed and the findings shows that organized collective learning, adversity and active experimentation with natural resource management will facilitate the reflection and practices towards 
sustainability. In another study by Moyer, et.al. (2014), individual learning for sustainability was explored and the findings showed that instrumental learning and embodied learning process such as observation, experiences, practical application and training are important in the sustainability learning. In addition, there are also other studies that focused on social learning instead of individual learning. A study conducted by Wals and Rodela (2014) and Dlouha (2013) found that social learning has a crucial contribution in the paradigm shift towards sustainability. While, Sterling (2010) had mapped the idea on transformative learning and its relation to sustainability by focusing on the challenges of unsustainable contemporary socio-ecological conditions of complexity and uncertainty present to educational processes and purposes. In a different view, Fabricatore and Lopez, (2012) have seen the potential of using games in sustainability learning by arguing that educating for sustainability demands learning approaches and environments that require the development of system thinking and problem solving. In another study carried out by the Zakirah and Amran (2011), it was shown that persuasive learning was effectiveness as a tool to promote sustainable practices in paddy farming in Malaysia.

\section{Learning Theories}

To understand sustainability learning, one has to first understand the learning theories. Exploration of learning theory is beneficial to the managers, policy-level leaders, learning specialists and consultants because it provides information that will allow them to make better decisions and better learning experiences (Knowles, et. al., 2011). Table 2 shows the learning theories which underlie sustainability learning process.

Table 2 Learning theories underlying the sustainability learning process

\begin{tabular}{|l|l|l|}
\hline Theory & Explanation & Author \\
\hline Adult learning theory & $\begin{array}{l}\text { Specifically developed to understand how adult learn. The model of andragogy is } \\
\text { based on several assumption: } \\
\text { Adults need to know the reason why they learn something } \\
\text { Adults need to be self-directed } \\
\text { Adults prefer to bring work-related experience into the learning process. } \\
\text { Adults participate in the learning experience based on problem-centred approach to } \\
\text { learn. } \\
\text { Adult need extrinsic and intrinsic motivation factor as motivator to learn. }\end{array}$ & Knowles \\
\hline Social learning & $\begin{array}{l}\text { Emphasized that, people learn by observing other person as a model, whom they } \\
\text { believe are credible and knowledgeable. Based on social learning theory, behaviour } \\
\text { that observed by observer that reinforced or rewarded tends to be repeated by the } \\
\text { individual. There are two ways how individual learn based on social learning. First, } \\
\text { experience the consequences of learned skills and behaviour directly and second, } \\
\text { seeing the consequences through the observation of other behaviours. }\end{array}$ & Nours. \\
\hline $\begin{array}{l}\text { (Individual learning) } \\
\text { Experiential theory }\end{array}$ & $\begin{array}{l}\text { Introduced by Kolb (1984) emphasizing on 'learning by doing' and the knowledge } \\
\text { creating are forming from the transformation of experience. The concrete } \\
\text { experience will influence the cognitive reflection that will lead people to change } \\
\text { the understanding and knowledge that guide creation of different action. }\end{array}$ & Lankester (2013) \\
\hline $\begin{array}{l}\text { Transformative learning } \\
\text { theory }\end{array}$ & $\begin{array}{l}\text { Originated from the work of adult educationalist Mezirow (1978) which refers to } \\
\text { qualitative move in perception and meaning of the learner in the learning } \\
\text { experience. Transformative learning is commonly associated with the meaning of } \\
\text { learning that touches deeper levels of knowing and meaning, which will influence } \\
\text { our immediate concrete levels of knowing, perception and action accordingly. }\end{array}$ & \\
\hline
\end{tabular}

\section{Contextual Factors in the Learning Process}

The previous studies have shown the importance in considering contextual factors in the studying sustainability learning process (Henry, 2009; Lankester, 2013; Wals and Rodela, 2014; Moyer, et. al, 2014). Table 3 shows the contextual factors concern by certain authors regards to sustainability learning process. 
Table 3 Selected contextual factors

\begin{tabular}{|l|l|}
\hline Author & Contextual Factors \\
\hline Henry (2009) & $\begin{array}{l}\text { Factors such as social influence, internal belief systems, individual experience and endogenous network } \\
\text { are greatly influence by the context where the learning has imposed. }\end{array}$ \\
\hline Ballard (2005) & $\begin{array}{l}\text { There are several contextual factors that influence change programme for sustainability has been } \\
\text { discussed in Ballard's study. The contextual factors are: 1) individual subjective factors that are more } \\
\text { to behavioural elements of the individuals such as emotions, perceptions, habits, belief, values and } \\
\text { norms; 2) individual objective factors including role, skills and knowledge and individual socio- } \\
\text { demographics; 3) collective subjective factors that are cultural solidarities, level of wider organizational } \\
\text { and social development and regimes of denial and acknowledgement; 4) collective objective factors for } \\
\text { instance economic, technological and social lock-in, legal and environmental. }\end{array}$ \\
\hline Alshahi (2008) & $\begin{array}{l}\text { Categorized contextual factors into two categories that is external and internal context. External } \\
\text { contextual factor or knows as outer context are referring to political context, social context and } \\
\text { interpretation and perception of the organization that operated internationally. At the other hand, inner } \\
\text { context (internal factors) refers to organizational strategy, structure, and culture and management } \\
\text { process. }\end{array}$ \\
\hline Coetzer and Perry (2008) & $\begin{array}{l}\text { Described the key factors in influencing employees in learning that can be categorized into four themes } \\
\text { that are factors in the external business environment, factors in the work environment, learning potential } \\
\text { of the job itself and learning orientation of employees. }\end{array}$ \\
\hline Lee, et. al. (2013) & $\begin{array}{l}\text { Identified two contextual determinants of ambidextrous learning that will influence the performance in } \\
\text { organization. The factors are divided into external setting (environmental dimension) and internal } \\
\text { setting (firm size). }\end{array}$ \\
\hline
\end{tabular}
factors.

Based on the above table, the contextual factors highlighted by the previous authors can be categorized as organizational and individual

\section{HR(D) and Sustainability}

Rising emphasis on business sustainability has brought implications to HR theory and practice. HRM refers to the policies, practices and systems that will influence employees' behaviours, attitudes and performance (Noe, 2013). Noe (2013) highlights the importance of the HRM to the business organization especially in supporting the organization goals through what has been called as strategic HRM. Previously, sustainability seldom appeared in HR theory and practice (Boudreau and Ramstad, 2005). However, given the upcoming trends of sustainability in the world of business, HR is forced to embrace sustainability. The significance of the HR function in supporting the organization's vision towards sustainability is due to several reasons (Jabbour and Santos, 2008). Firstly, HR function plays a great potential in advancing sustainability in organizations. Secondly, HRM needs to embrace the challenges in the contemporary world and recognize that businesses need long-term HR strategies to achieve sustainable economic performance. Thirdly, stimulation of organizational sustainability is the new paradigm shift that must be retained by any organization nowadays. Finally, modern HRM should be more effective in satisfying various organizational stakeholders. These justifications are consistent with a pioneering study by Boudreau and Ramstad (2005) who urged for closer collaborations between HR with organizations' leaders to achieve holistic organizational effectiveness beyond the traditional economic performance. The movement from traditional HR function to 'talentship' concept in supporting sustainability will help the organizations to improve their effectiveness in economic, social and environmental terms.

The importance of HR in organizational sustainability initiatives points to the need to develop employees accordingly. Within the realm of HRM, HRD has been noted as one of the key players in developing corporate social responsibility and sustainability (Garavan and McGuire, 2010). HRD is a concept that focuses on how to develop individual's personal and organizational skills, knowledge and abilities with the primary objective of ensuring a better integration between work and learning (Garavan and Carbery, 2012). The potential role of HRD in achieving business sustainability is vast, yet this area has not been fully developed except in the recent years. For instance, a study by Kim (2012) highlights the present HRD theory and practice has not sufficiently covered the issues related to societal development. This is supported by Russ (2012) whose study discussed the mutual constructive potential between sustainability and HRD in shaping employees' mental models and values through sustainable learning programmes. Similarly, Ardichvili (2013) also notes the relations by proposing a model that linking HRD with sustainability, ethics and corporate social responsibility. Ardichvili (2013) found that HRD has a significant control on the model construct through education and training.

\subsection{HOLISTIC SUSTAINABILITY LEARNING FRAMEWORK}

Based on the above literature analysis, the following framework (Figure 1) is conceptualized. The Holistic Sustainability Learning Framework depicts a holistic process to understand sustainability learning in organization. As stated in Knowles, et.al. (2011), the framework characterizes the universe as a unitary, interactive and developing organism. The framework perceives the essence of activity rather than static elements. Thus, the Holistic Sustainability Learning Framework shows the interaction between all the dimensions in the structured model. Organization sustainability goals should affect the formulation of the organization's strategic HRD. Thus, all HRD initiatives should be aligned towards achieving sustainability business practices as aimed by the organizations. As argued earlier, HRD plays a role in inculcating relevant knowledge, skills and attitudes in employees which support sustainability. Learning programmes in the form of formal and informal learning act as a medium for the sustainability learning process. Previous studies have shown the significant roles of individual learning, social learning and transformative learning in the process of sustainability learning in organizations. The outer circle shows that, the process of sustainability learning in the organization is influenced by individual and organizational factors. 


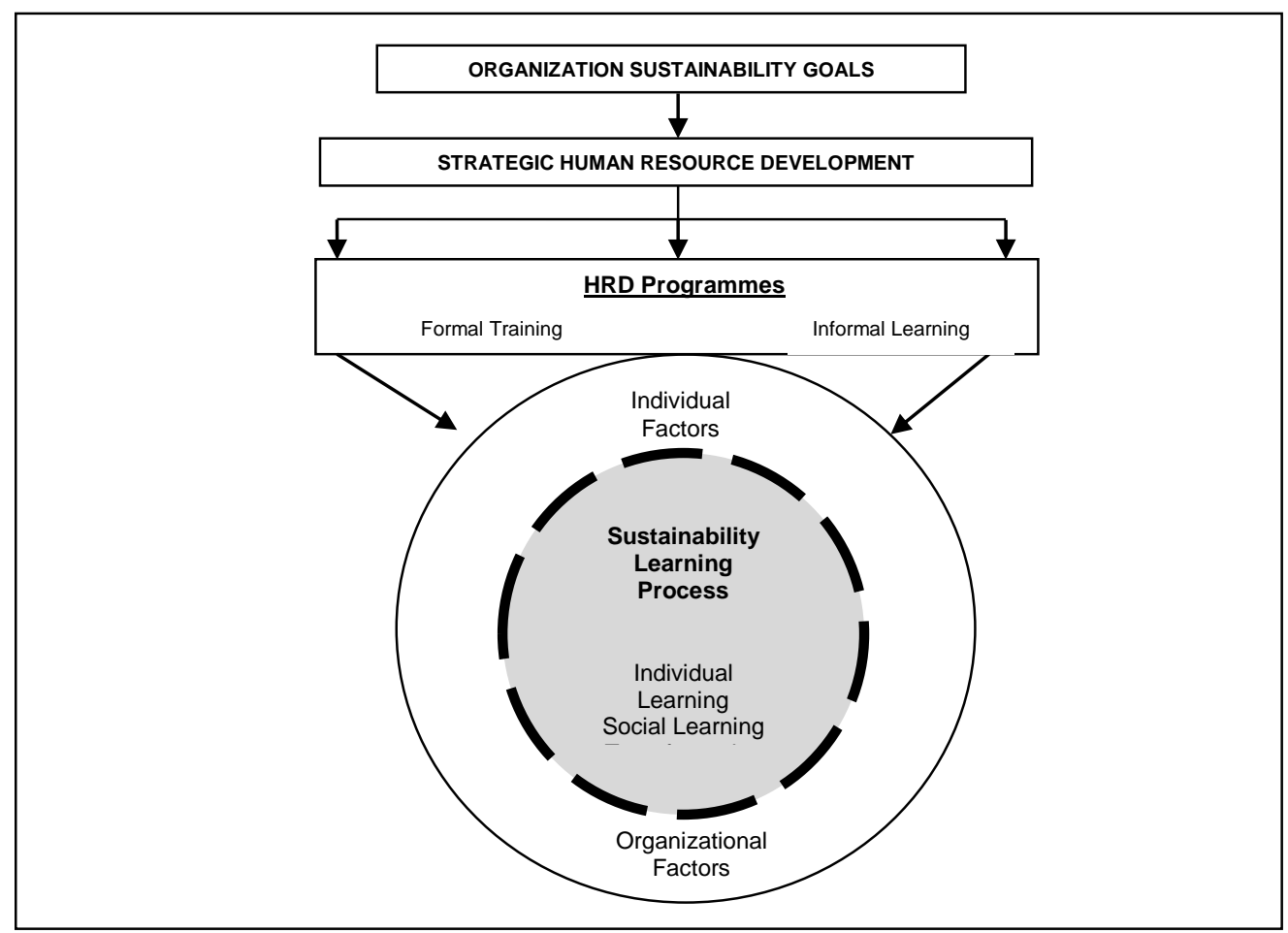

Figure 1 Holistic sustainability learning framework

\subsection{CONCLUSION}

The aim of this paper is to conceptualize a framework of sustainability learning in organizations and to understand the pivotal role that HRD plays in facilitating the learning process. Through reviews of various literatures in the areas of sustainability, HRD and learning theories, the paper has highlighted several points. The paper has echoed other scholars in the field regarding the grave importance of sustainability in the theory and practice of organizations with a specific focus to the discipline of HR. It then analyzed gaps in the current understanding on sustainability learning through HRD programmes. It has concluded not only that knowledge on the relation between HRD and sustainability is still relatively limited, but despite of the important role of learning programmes in developing sustainability practices in employees, the existing knowledge in how sustainability learning actually occurs in organizations is not fully understood. The paper has argued that some contextual factors have not been analyzed and captured in the existing sustainability learning models. Against this backdrop, the paper proposed the Holistic Sustainability Learning Model which is argued to contain important elements which may be involved in the process of sustainability learning in HRD programmes.

This paper attempts to bring a new perspective to the understanding of sustainability learning by developing a conceptual framework to examine the role of HRD in cultivating sustainability learning in organizations. Integration of the three learning theories as explained above will provide a holistic view. However, a cautionary note needs to be made. The framework is only based on literature reviews. It depicts a proposed, tentative framework. Whether or not the framework reflects the real scenario in organizations is yet to be empirically and rigorously investigated. The paper hence contributes by providing a point of departure to researchers in the topic in terms of the elements that may need to be considered in the study of sustainability learning.

\section{References}

Alshahi, M. (2008). How Contextual Factors Shape Organizational Change Implementation, available online www.brunel.ac.uk/data/asset/phdsimp

Amini, M. And Bienstock, C.C. (2014). Corporate sustainability: an integrative definition and framework to evaluate corporate practice and guide academic research, Journal of Cleaner Production, 76, 12-19.

Atkisson, A., Hatcher, R.L, Green, S. (2004). Introducing pyramid: A versatile process and planning tool for accelerating sustainable development, The Natural Advantage of Nations, Draft Version 4

Armstrong, M. (2001). A Handbook of Human Resource Management Practice, Eight Edition

Arevalo, J.A, Castello, I, Colle, S.D, Lenssen, G., Neumann, K and Zollo, M. (2011), Introduction to the special issue: integrating sustainability in business models, Journal of Management Development, 30 (10), 941-954

Ardichivili, A. (2013). The role of HRD in CSR, Sustainability and Ethics: A relational model, Human Resource Development Review, 12(4), 456-473

Angheluta, S.P, Margina, O, Zaharia, A and Arionesei, G. (2014), The role of human resource in sustainable development of the energy sector. Ecoforum Journal, 3(1),

Batra, M.M. (2012). The Sustainability Challenge and its Business Solution, $C F, 10$ (1), 182-190

Ballard, D. (2005), Using learning process to promote change for sustainable development, Action Research, 3(2), 135-156

Bansal, P and DesJardine, M.R (2014). Business Sustainability: It is about time. Strategic Organization, 12 (1), $70-78$

Baharin, I and Abdullah, A. (2011). Sustainable business in Malaysia: The need for talent ecosystem, International Journal of Basic and Applied Sciences, 11(4), 30- 
Canziani, B. F., Sonmez, S., Hsieh, Y.J \& Byrd,E.T. (2012). A learning theory framework for sustainability education in tourism, Journal of Teaching in Travel and Tourism, $12(1), 3-20$

Coetzer, A. and Perry, M. (2008). Factors influencing employee learning in small business, Education and Training, 50(8/09), 648-660

Coleman, G. (2013). Sustainability as a learning challenge, Journal of Management Development, 32(3), 258-267

Craig, C.A and Allen, M.W (2013). Sustainability information sources: employee knowledge, perceptions and learning, Journal of Communication Management, 17(4), 292-307

Diesendorf, M. (2000). Sustainability and sustainable development, in Dunphy, D., Benveniste, J., Griffith, A and Sutton, P (eds), Sustainability: The Corporate Challenge of the $21^{\text {st }}$ Century, Sydney: Allen \& Unwin, Chap.2, 19-37

DeLong and Mehalik (2013). Opportunities and obstacles on the path to business sustainability, American Journal of Management, 13(3), 98-112

Dlouha, J., Barton, A., Janouskova, S. and Dlouhy, J. (2013). Social learning indicators in sustainability-oriented regional learning networks, Journal of Cleaner Production, 49, 64-73

Elkington, J. (1994). Towards sustainable corporation: Win-win business strategies for sustainable development. California Management Review, 36(2), 90-100

Fabricatore, C. and Lopez, X. (2012). Sustainability learning through gaming: An exploratory study, Electronic Journal of e-Learning, 10(2), 209-222

Garavan, T.N. and Carbery, R. (2012). Strategic Human Resource Development, In International Human Resource Development: Learning, Education and Training for Individuals and Organizations, $\left(3^{\text {rd }}\right.$ ed), 23-44. London: Kogan Page

Garavan, T.N and McGuire, D (2010), Human Resource Development and Society: Human Resource Development's role in embedding corporate social responsibility, sustainability and ethics in organization, Advances in Developing Human Resources, 12(5), 487-507

Garg, B. (2014). Human resource driving force of sustainable business practices, International Journal of Innovative Research and Development, 3(7), 378-382

Hansmann, R. (2010). "Sustainability learning": An introduction to the concept and its motivational aspects, Sustainability, 2, 2873-2897

Henry, A. D. (2009). The challenges of learning for sustainability: A prolegomenon theory, Human Ecology Review, 16(2), 131-140

Kim, N. (2012). Societal development through human resource development: contexts and key change agents, Advances in Developing Human Resources, 14(3), 239250

Knowles, M.S, Holton, E.F and Swanson, R.A., The Adult Learner: The Definitive Classic in Adult Education and Human Resource Development, $7^{\text {th }}$ Edition, Butterworth-Heinemann

Lankester, A.J. (2013). Conceptual and operational understanding of learning for Sustainability: A case study of the beef industry in north- Eastern Australia, Journal of Environmental Management, 119, 182-193

Lee, C.Y, Wu,H.L and Liu, C.Y . (2013). Contextual determinants of ambidextrous learning: Evidence from industrial firms in four industrialized countries, IEEE Transactions on Engineering Management, 60(3), 529-540

McBride, M. (2011). Triple bottom line by design: Leading as if life matters, The Design Management Institute, 22(1), 6-14

Muthuveloo, R and Ping, T.A (2013). Achieving business sustainability via I-Top Model, American Journal of economics and Business Administration, 5(1), 15-21

Moyer, J.M, Sinclair, A.J and Diduck, A.P. (2014). Learning for sustainability among faith-based organizations in Kenya, Environmental Management, 54, 360-372

Noe, R.A (2013). Employee Training and Development, $6^{\text {th }}$ Edition, McGraw-Hill International Edition.

Saadatian, O., Haw, L.C, Mat, S. and Sopian, K. (2012). Perspective of sustainable development in Malaysia, International Journal of Energy and Environment, 6(2), 260-267

Schneider, H.D., Livitz, I.E and Schneider, D. (2013). Sustainable learning for sustainability, Journal of Organizational Transformation \& Social Change, 10(2), 124147

Sterling, S. (2010), Transformative learning and sustainability: sketching the conceptual ground, Learning and Teaching in Higher Education, 5, 17-33

Slaper, T.F. and Hall, T.J. (2011). The triple bottom line: What is it and how does it work?, Indiana Business Review, .4-8

Shaharir, B.M.Z and Alinor, M.B.A.K. (2012). The need for a new definitions of sustainability, Journal of Indonesian Economy and Business, 28(2), 257-274

Thomas, T.E and Lamm, E (2012), Legitimacy and organizational sustainability, Journal of Business Ethics, 110, 191-203.

Tollin, K and Vej, J. (2012). Sustainability in business: Understanding meanings, triggers and enablers, Journal of Strategic Marketing, 20(7), 625-641.

Velazquez, L.E., Esquer, J. and Munguia, N.E. (2011). Sustainable learning organization, The Learning Organization, 18(1), 36-44.

Wagner, B and Svensson, G (2014). A framework to navigate sustainability (TBS) model, European Business Review, 26(4), 340-367.

Wals A.E.J and Rodela, R. (2014). Social learning towards sustainability: Problematic, Perspectives and promise, NJAS-Wageningen Journal of Life Sciences, 69, 1-3.

Wang, G.G and Wang, J. (2004). Toward a theory of human resource development learning participation, Human Resource Development Review, 3(4), $326-353$.

Waaa, T., Huge, J., Verbruggen, A. and Wright, T. (2011). Sustainable development: A bird's eye view, Sustainability, 3, 1637-1661.

Zakirah, O. and Amran, M. (2011). Design strategies to persuasive learning for promoting sustainable practices in paddy farming, American Journal of Economics and Business Administration, 3(1), 197-202. 